\title{
Responses of Leaf Hydraulic Traits of Schoenoplectus Tabernaemontani To Increasing Temperature and $\mathrm{CO}_{2}$ Concentrations
}

\author{
Yao Zhao \\ Southwest Forestry University \\ Mei SUN ( $\square$ sm0510215@163.com) \\ Southwest Forestry University \\ Huijun Guo \\ Southwest Forestry University \\ Chunhui Feng \\ Southwest Forestry University \\ Zhenya Liu \\ Southwest Forestry University \\ Junping Xu \\ Southwest Forestry University
}

\section{Original Article}

Keywords: Hydraulic traits, ecological response, plateau wetlands, climate change.

Posted Date: September 21st, 2021

DOI: https://doi.org/10.21203/rs.3.rs-895723/v1

License: (c) (i) This work is licensed under a Creative Commons Attribution 4.0 International License. Read Full License

Version of Record: A version of this preprint was published at Botanical Studies on January 24th, 2022. See the published version at https://doi.org/10.1186/s40529-022-00331-2. 


\section{Abstract \\ Background}

Against the background of a changing climate, the responses of functional traits of plateau wetland plants to increasing temperatures and $\mathrm{CO}_{2}$ concentrations need to be understood. Hydraulic traits are the key for plants to maintain their ecological functions and affect their growth and survival. However, few studies have comprehensively considered the response strategies of wetland plants' hydraulic traits to environmental changes in the context of water and matter transport, loss, and retention. According to the latest IPCC prediction results, we performed experiments under increased temperature $\left(2^{\circ} \mathrm{C}\right)$ and $\mathrm{CO}_{2}$ levels (850 $\mu \mathrm{mol} / \mathrm{mol})$ in an artificial Sealed-top Chamber (STC) to investigate the responses of the hydraulic characteristics of Schoenoplectus tabernaemontani, the dominant species in plateau wetlands in China.

\section{Results}

Compared with the CK group, net photosynthetic rate, transpiration rate, stomatal length, cuticle thickness, vascular bundle length, vascular bundle width, and vascular bundle area of $S$. tabernaemontani in the ET group were significantly reduced, whereas stomatal density and vein density increased significantly. Compared with the CK group, the hydraulic traits of $S$. tabernaemontani in the EC group were reduced considerably in stomatal length and cuticle thickness but increased dramatically in stomatal density, and there were no significant differences between other parameter values and the control group. Net photosynthetic rate was significantly positively correlated with stomatal length, cuticle thickness, and vascular bundle length, and stomatal conductance was significantly positively correlated with cuticle thickness. The transpiration rate was significantly positively correlated with cuticle thickness, epidermal cell area, vascular bundle length, vascular bundle width, and vascular bundle area. Regarding the hydraulic traits, there was a significant negative correlation between stomatal density and stomatal length, or cuticle thickness, and a significant positive correlation between the latter two. The epidermal cell area was significantly positively correlated with epidermal thickness, vascular bundle length, vascular bundle width, and vascular bundle area

\section{Conclusions}

Increased temperature and $\mathrm{CO}_{2}$ levels are not conducive to the photosynthetic activity of $S$. tabernaemontani. Photosynthetic rate, stomatal density and size, vein density, epidermal structure size, and vascular bundle size play an essential role in the adaptation of this species to changes in temperature and $\mathrm{CO}_{2}$ concentration. In the process of adaptation, hydraulic traits are not isolated from each other, and there is a functional association among traits. This study provide a scientific basis for the management and protection of plateau wetlands.

\section{Introduction}

Climate warming and increasing $\mathrm{CO}_{2}$ concentrations are the two main characteristics of global climate change. According to the fifth IPCC global climate change assessment report, the global average surface air temperature at the end of this century will increase by $0.3-4.8^{\circ} \mathrm{C}$ based on data from $1986-2005$, and the concentration of $\mathrm{CO}_{2}$ in the atmosphere will reach $540-970$ $\mu \mathrm{mol} \cdot \mathrm{mol}-1$ (IPCC, 2014). Many studies have shown that climate change, characterized by warming and rising $\mathrm{CO}_{2}$ concentrations, significantly affects the structure and function of the earth's ecosystems (Xia et al. 2020; Feng et al. 2020).

Wetland ecosystems are unique habitats formed by land and water and play a vital role in maintaining biodiversity and providing ecosystem services (Li et al. 2018). However, they are highly vulnerable to climatic changes (Day et al. 2005). Plateau wetlands are an essential part of Chinese ecological environment. Because of their high elevation and specific terrain, they are extremely sensitive to climate change (Feng et al. 2019). Wetland plants, as the functional carriers of wetlands, show significant changes in their morphology, structure, and physiological functions under a changing climate, indicating adaptation to

Page $2 / 14$ 
environmental changes (Zhao et al. 2009). In this context, studying the responses of the functional traits of plateau wetland plants to changing climate characteristics is an essential aspect of exploring and predicting change laws in wetland ecosystems and can facilitate the prediction of plateau wetland evolution and ecological function processes (Guittar et al. 2016).

Plant hydraulic traits are the general term for a class of functional traits that can significantly affect water transmission, loss, and retention, thereby affecting physiological functions such as photosynthetic productivity (Lawren et al. 2006). The stomata are the main channels for water vapor exchange between plants and the atmosphere, and their size and density changes directly affect the water loss rate and sensitivity of plants (Zuo et al. 2005). The cuticle, epidermal cells, and other epidermal structures are essential for plant water conservation ( $\mathrm{Li}$ et al. 2016), and the vascular bundle traits play an important role in water transport and distribution in plants (Fang et al. 2003). Terrestrial plants are frequently constrained by water availability, and changes in hydraulic traits and functional regulation are the key to the growth, survival, and development of land plants. (Anderegg et al. 2016; Sack et al. 2016). Hydraulic traits are also the main parameters reflecting the functions of wetland plants such as erect state, resistance to mechanical damage, water vapor and material exchange, water and material transmission, and photosynthetic production, among others. In this sense, focusing on the adaptability of the hydraulic traits of wetland plants is crucial when exploring their ecological adaptation mechanisms, with consequent information on wetland protection. However, systematic research on the hydraulic traits of plateau wetland plants is still scarce.

Like terrestrial plants, wetland plants show significant changes in hydraulic traits in different climatic environments, reflecting their response strategies. Earlier studies on the ecological responses of wetland plants on the Southwest Plateau of China have shown that at elevated temperatures, Hippuris vulgaris increased the aboveground stem vascular structure of the ducts, sieves, and vascular bundles, along with the pronounced development of the belowground vascular network of the ducts and sieves to enhance mechanical supportability and water retention ability (Guan et al. 2019). Similarly, Schoenoplectus tabernaemontani significantly reduces its vessel perimeter, area, and cross-sectional surface, the cross-sectional area of the sieve tube, and its net photosynthetic rate but substantially increases the cross-sectional density of the sieve tube to adapt to higher temperatures (Feng et al. 2020). In addition, warming significantly affects the light and $\mathrm{CO}_{2}$ use of dominant plants in the wetland lakeside zone of the Northwest Yunnan Plateau, with different species showing different responses. Zizania latifolia adapts to warming by reducing its photosynthetic $\mathrm{CO}_{2}$ use capacity and net photosynthetic rate. The species Sparganium stoloniferum adapts to warming by increasing its light saturation point, light energy use range, and net photosynthetic rate (Liu et al. 2017). At high $\mathrm{CO}_{2}$ concentrations, $S$. tabernaemontani can significantly increase its net photosynthetic rate, intercellular $\mathrm{CO}_{2}$ concentration, water use efficiency, and biomass and reduces stomatal conductance and transpiration rate (Xu et al. 2016). By inhibiting the photosynthetic mechanism of the leaves, Vallisneria natans lowers its photosynthetic capacity to adapt to changing atmospheric $\mathrm{CO}_{2}$ concentrations (Han et al. 2017). These studies reflect the interspecific differences in plateau wetland plants in adapting to increasing temperatures and $\mathrm{CO}_{2}$ concentrations, improving our understanding of the functional responses of plateau wetland plants to a changing climate. However, these studies did not comprehensively consider the transportation, loss, and maintenance of water and substances by plants from the hydraulics perspective and neglected the relationship between corresponding traits and photosynthetic production.

This study used S. tabernaemontani, the dominant plant species of the plateau wetland in the Yunnan area, as the research object and applied the Sealed-top Chamber (STC) to simulate increases in temperature and $\mathrm{CO}_{2}$ concentration. By determining stomatal density and size, vein density, epidermal structure size, vascular bundle structure, photosynthetic gas exchange parameters, and other hydraulic traits, the responses of $S$. tabernaemontani to increasing temperature and $\mathrm{CO}_{2}$ levels were determined. This study provides a scientific basis for the management and protection of plateau wetlands.

\section{Materials And Methods}

\section{Research materials and experimental settings}


Schoenoplectus tabernaemontani is widely distributed in the lakeside zone of plateau wetlands in the Yunnan area, China. The dominance of $S$. tabernaemontani at different elevations is discrepant, and is the species is susceptible to changes in environmental factors. It shows solid ecological plasticity, making it an ideal material for studying the responses of functional traits to changes in environmental factors and to assess the adaptability of wetland plant functional traits to overall climatic changes.

From March to April 2018, healthy and evenly growing S. tabernaemontani specimens in the lakeside zone of Dianchi Lake were selected and transplanted into an experimental barrel with a diameter of $35 \mathrm{~cm}$ and a height of $25 \mathrm{~cm}$. The cultivation substrate was in-situ soil from the lakeside zone of Dianchi Lake, with each plant receiving the same amount of soil. After 14 days of adaptation under natural conditions, the seedlings were randomly placed in three Sealed-top chambers (STC) with four pots in each room. To maintain uniform lighting conditions and eliminate edge effects, the pots in each growth chamber were placed in the center of the control room and randomly located at a circle radius of $0.85 \mathrm{~m}$ (the growth chamber radius was $1.7 \mathrm{~m}$ ). The latest IPCC-predicted temperature and $\mathrm{CO}_{2}$ concentration increase was simulated in the first growth room as control check (CK). In one growth chamber, the temperature was increased by $2^{\circ} \mathrm{C}$ as a temperature increase treatment (ET), and the $\mathrm{CO}_{2}$ concentration of the other growth chamber was set to $850 \mu \mathrm{mol} \cdot \mathrm{mol}-1$ as a $\mathrm{CO}_{2}$ concentration doubling treatment (EC); the other environmental factors remained the same. The plants were watered twice a week to maintain uniform flooding depth and growth conditions during the experimental period. The plants were grown in the growing room for 4 months to adapt to the warming environment.

\section{Plant functional traits}

On sunny days, from 08:30-11:30 in the morning, we selected three plants from four pots and measured photosynthesis using a Li-6400 portable photosynthesis instrument (LI-6400, LI-COR, Nebraska, USA). From each plant, two fully developed mature leaves were selected, and at $20 \mathrm{~cm}$ from the top of the leaf, in situ determination of the net photosynthetic rate $\left(\mathrm{Pn}, \mu \mathrm{mol} \cdot \mathrm{m}^{-}\right.$ $\left.2 \cdot \mathrm{s}^{-1}\right)$, stomatal conductance $\left(\mathrm{Gs}, \mathrm{mol} \cdot \mathrm{m}^{-2} \cdot \mathrm{s}^{-1}\right)$, and transpiration rate $\left(\mathrm{Tr}, \mathrm{mmol} \cdot \mathrm{m}^{-2} \cdot \mathrm{s}^{-1}\right)$ was performed. During the measurement, the light intensity inside the leaf chamber was set to $1,500 \mu \mathrm{mol} \cdot \mathrm{m}^{-2} \cdot \mathrm{s}^{-1}$, the leaf temperature was kept at 22$24^{\circ} \mathrm{C}$, the flow rate was set to $500 \mu \mathrm{mol} \cdot \mathrm{s}^{-1}$, and the indoor CO2 mole fraction was set to $425 \mu \mathrm{mol} \cdot \mathrm{s}^{-1} \cdot \mathrm{mol}^{-1}$.

The leaves used for photosynthesis measurement were cut down to a length of about $15 \mathrm{~cm}$ from the middle part, sealed in a bag containing wet paper balls, and stored in a box until analysis of leaf anatomy and determination of hydraulic traits. Part of the leaves was cut, and transparent nail polish was applied on the surface. After drying, the surface was teared off to obtain the surface print, which was placed on a glass slide to observe the stomata of $S$. tabernaemontani under an optical microscope (Leica Inc., DM2500, Bensheim, Germany). Images were taken and processed using the Image J (v. 1.48; http: //rsb.info.nih.gov/ij/) image processing software. The number of stomata in each picture was determined and stoma length was measured $(\mathrm{SL}, \mu \mathrm{m})$. Stoma density $\left(\mathrm{SD}, \mathrm{No} . / \mathrm{mm}^{2}\right)$ was calculated as the number of stomata per unit area.

The cross-section of $S$. tabernaemontani was cut, and thin slices were selected and stained with toluidine blue to prepare watermounted slices, avoiding the epidermis. In the middle section, pictures of the vascular bundle structure were taken under an optical microscope. The following parameters were measured: vascular bundle length (VBL, $\mu \mathrm{m})$, vascular bundle width (VBW, $\mu \mathrm{m})$, vascular bundle area $\left(\mathrm{VBA}, \mu \mathrm{m}^{2}\right)$, and leaf vein density $\left(\mathrm{VD}, \mathrm{mm} / \mathrm{mm}^{2}\right)$, using the Image $\mathrm{J}$ image processing software. Subsequently, the lens was adjusted to the epidermal structure, which was observed under an optical microscope and photographed. Via the Image $J$ image-processing, the following characteristics were measured: cuticle thickness (CT, $\mu \mathrm{m})$, epidermal thickness $(E T, \mu m)$, and epidermal cell area $\left(E A, \mu m^{2}\right)$. In this study, the repetition amount of each hydraulic trait is 30 , and the specific measured traits and their abbreviations are shown in Table 1. 
Table 1

Functional traits of Schoenoplectus tabernaemontani measured in this study and the results of principal components analysis.

\begin{tabular}{|lllll|}
\hline Vascular bundle traits & Abbreviations & Unit & PC1 & PC2 \\
\hline Net photosynthetic rate & $\mathrm{P}_{\mathrm{n}}$ & $\mu \mathrm{mol} \cdot \mathrm{m}^{-2} \cdot \mathrm{s}^{-1}$ & $0.846^{\star *}$ & -0.224 \\
\hline Stomatal conductance & $\mathrm{Gs}$ & $\mathrm{mol} \cdot \mathrm{m}^{-2} \cdot \mathrm{s}^{-1}$ & $0.692^{\star}$ & -0.396 \\
\hline Transpiration rate & $\mathrm{Tr}$ & $\mathrm{mmol} \cdot \mathrm{m}^{-2} \cdot \mathrm{s}^{-1}$ & $0.959^{\star *}$ & 0.003 \\
\hline Stomatal length & $\mathrm{SL}$ & $\mu \mathrm{m}$ & $0.698^{*}$ & -0.576 \\
\hline Stomatal density & $\mathrm{SD}$ & $\mathrm{No} . / \mathrm{mm}^{2}$ & -0.571 & $0.659 *$ \\
\hline Vein density & $\mathrm{VD}$ & $\mathrm{mm} / \mathrm{mm}^{2}$ & -0.587 & -0.159 \\
\hline Cuticle thickness & $\mathrm{CT}$ & $\mu \mathrm{m}$ & 0.655 & $-0.697 *$ \\
\hline Epidermal thickness & $\mathrm{ET}$ & $\mu \mathrm{m}$ & 0.530 & 0.549 \\
\hline Epidermal cell area & $\mathrm{EA}$ & $\mu \mathrm{m}^{2}$ & $0.725^{*}$ & 0.391 \\
\hline Vascular bundle length & $\mathrm{VBL}$ & $\mu \mathrm{m}$ & $0.921 * \star$ & 0.260 \\
\hline Vascular bundle width & $\mathrm{VBW}$ & $\mu \mathrm{m}$ & $0.832^{\star *}$ & 0.462 \\
\hline Vascular bundle area & $\mathrm{VBA}$ & $\mu \mathrm{m}^{2}$ & $0.738^{*}$ & 0.546 \\
\hline$* P<0.05 ; * * P 0.01$. & & & & \\
\hline
\end{tabular}

\section{Data analysis}

Using the R (4.0.3) statistical analysis software, and through its built-in "vegan" program package, one-way ANOVA and LSD were applied for multiple comparisons to compare various functional traits of S.tabernaemontani under different treatments. The difference test was performed at a statistical significance level was $P<0.05$. Principal components analysis (PCA) was used to obtain the degree of variation of various functional traits in response to influencing factors. Pearson's correlation analysis was performed on the functional traits of $S$. tabernaemontani to reveal the synergistic relationships among its functional traits.

\section{Results}

\section{Responses of Schoenoplectus tabernaemontani hydraulic traits to temperature and $\mathrm{CO}_{2}$ increases}

A $2^{\circ} \mathrm{C}$ increase in temperature had a more substantial effect on the hydraulic traits of $S$. tabernaemontani than a doubling of the $\mathrm{CO}_{2}$ concentration. The temperature increase and $\mathrm{CO}_{2}$ concentration doubling treatments generally reduced photosynthetic capacity, stomatal size, and cuticle thickness and increased the stomatal density of $S$. tabernaemontani. However, the response trend of $S$. tabernaemontani hydraulic traits to warming and $\mathrm{CO}_{2}$ concentration doubling is not precisely the same (Fig. 1). Compared with the CK group, net photosynthetic rate, transpiration rate, stomatal length, cuticle thickness, vascular bundle length, vascular bundle width, and vascular bundle area of $S$. tabernaemontani in the ET group were significantly reduced, whereas stomatal density and vein density increased significantly. Compared with the CK group, the hydraulic traits of $S$. tabernaemontani in the EC group were reduced considerably in stomatal length and cuticle thickness but increased dramatically in stomatal density, and there were no significant differences between other parameter values and the control group. Compared with the EC group, net photosynthetic rate, stomatal density, and vascular bundle size (including vascular bundle length, width, and area) of $S$. tabernaemontani in the ET group were significantly lower, whereas vein density was substantially higher (Fig. 1).

\section{Correlation between hydraulic traits of Schoenoplectus tabernaemontani}


The first two main axes of the principal components analysis based on the hydraulic traits of $S$. tabernaemontani explained $54.93 \%$ and $20.99 \%$ of the total variation variance of functional traits, respectively (Fig. 2). The first principal axis was significantly positively correlated with net photosynthetic rate, stomatal conductance, transpiration rate, stomatal length, epidermal cell area, vascular bundle length, vascular bundle width, and vascular bundle area. The second principal axis was significantly positively correlated with stomatal density and significantly negatively correlated with cuticle thickness (Table 1). This indicates that these traits have important ecological significance in adapting to increased temperatures and $\mathrm{CO}_{2}$ concentrations.

Net photosynthetic rate was significantly positively correlated with stomatal length, cuticle thickness, and vascular bundle length, and stomatal conductance was significantly positively correlated with cuticle thickness. The transpiration rate was significantly positively correlated with cuticle thickness, epidermal cell area, vascular bundle length, vascular bundle width, and vascular bundle area (Table 3). Regarding the hydraulic traits, there was a significant negative correlation between stomatal density and stomatal length, or cuticle thickness, and a significant positive correlation between the latter two. The epidermal cell area was significantly positively correlated with epidermal thickness, vascular bundle length, vascular bundle width, and vascular bundle area (Table 3).

Table 2

Correlations among hydraulic traits of Schoenoplectus tabernaemontani.

\begin{tabular}{|c|c|c|c|c|c|c|c|c|c|c|c|}
\hline & Pn & Gs & $\mathrm{Tr}$ & SL & SD & VD & CT & ET & EA & VBL & VBW \\
\hline \multicolumn{12}{|l|}{$\mathrm{Pn}$} \\
\hline Gs & 0.629 & & & & & & & & & & \\
\hline $\operatorname{Tr}$ & 0.888 ** & $0.736^{*}$ & & & & & & & & & \\
\hline SL & $0.702 *$ & 0.551 & 0.593 & & & & & & & & \\
\hline SD & -0.445 & -0.622 & -0.425 & $-0.864^{\star \star}$ & & & & & & & \\
\hline VD & -0.580 & -0.267 & -0.567 & -0.167 & 0.127 & & & & & & \\
\hline CT & $0.699 *$ & $0.689 *$ & $0.660^{*}$ & $0.825^{\star \star}$ & $-0.776^{\star \star}$ & -0.286 & & & & & \\
\hline ET & 0.183 & 0.321 & 0.486 & 0.110 & -0.090 & -0.093 & -0.099 & & & & \\
\hline EA & 0.446 & 0.449 & $0.703^{*}$ & 0.365 & -0.235 & -0.063 & 0.174 & $0.891^{* *}$ & & & \\
\hline VBL & $0.666^{*}$ & 0.458 & $0.844^{\star *}$ & 0.477 & -0.398 & $-0.713^{*}$ & 0.450 & 0.528 & 0.655 & & \\
\hline VBW & 0.582 & 0.249 & 0.747 * & 0.350 & -0.231 & -0.649 & 0.230 & 0.592 & $0.700 *$ & 0.956 ** & \\
\hline VBA & 0.516 & 0.215 & $0.695^{\star}$ & 0.233 & -0.019 & -0.539 & 0.133 & 0.510 & $0.666^{\star}$ & $0.865^{\star \star}$ & $0.901^{* *}$ \\
\hline
\end{tabular}

\section{Discussion}

In this study, using S. tabernaemontani, a typical wetland emergent plant species in the Yunnan Plateau region, we determined photosynthetic gas exchange parameters, stomatal density and size, vascular bundle structure size, vein density and epidermal structure, and other hydraulic traits. Based on the latest IPCC climate prediction results, we simulated a temperature increase of $2{ }^{\circ} \mathrm{C}$ and a doubling of the $\mathrm{CO}_{2}$ concentration to explore the responses of $\mathrm{S}$. tabernaemontani hydraulic properties to climatic changes. Based on our results, increased temperature and $\mathrm{CO}_{2}$ levels are not conducive to the photosynthetic activity of $S$. tabernaemontani. Photosynthetic rate, stomatal density and size, vein density, epidermal structure size, and vascular bundle 
size play an essential role in the adaptation of this species to changes in temperature and $\mathrm{CO}_{2}$ concentration. In the process of adaptation, hydraulic traits are not isolated from each other, and there is a functional association among traits.

Different plant species show different responses to climate warming. Either on a global scale (Wright et al. 2004) or for individual plant species (Yin et al. 2008; Qi et al. 2012; Wang et al. 2017), most studies have shown that the photosynthetic capacity of most plants increases with increasing temperatures, mainly because the increase in temperature promotes the activity of plant photosynthetic enzymes and accelerate the gas exchange rate of plants, thereby promoting photosynthetic activity. Studies on specific types or individual species of plants have found that the relationship between plant photosynthetic capacity and temperature is not significant (Zhao et al. 2016) and decreases with increasing temperatures (Bresson et al. 2011; Liu et al. 2018) or first increases with temperature and then declines (Vo et al. 2015). This reflects the differences in the responses of different plants to temperature changes and indicates that the photosynthetic capacity is not only affected by temperature but also by other environmental factors. Under different environmental conditions and in various ecosystems, there are various controlling factors. For example, plants in high-elevation areas are strongly affected by temperature, light intensity, $\mathrm{CO}_{2}$ concentration, and microclimatic conditions (Bresson et al. 2011; Sun et al. 2016). Epiphytes are significantly affected by water availability and light conditions (Sun et al. 2014), whereas wetland plants are generally largely affected by temperature, $\mathrm{CO}_{2}$ concentration, water, sediment environment, among others (Zhang et al. 2021). In our study, the photosynthetic and transpiration rates of $S$. tabernaemontani decreased significantly under increasing temperatures, reflecting the decline in photosynthetic capacity and productivity. This is consistent with the results of Qi et al. 2012) for Phragmites australis and the in-situ field study by our research team in the Napahai of Shangri-La, Yunnan (Feng et al. 2020), further confirming that against the background of a changing climate, warming is not conducive to photosynthetic production and biomass accumulation of $S$. tabernaemontani. Our earlier field investigations on the plateau area also found that this species is the dominant aquaticterrestrial ecotone species in the Napahai area at an elevation of 3,266 meters and an average temperature of $5.4^{\circ} \mathrm{C}$, with its photosynthetic rate exceeding $30 \mu \mathrm{mol} \cdot \mathrm{m}^{-2} \cdot \mathrm{s}^{-1}$. In contrast, in the Lashihai area at an elevation of 2,437 meters and an average temperature of $13.6^{\circ} \mathrm{C}$, it is more slender and short and does not dominate the plant community, with a photosynthetic rate only occasionally reaching $20 \mu \mathrm{mol} \cdot \mathrm{m}^{-2} \cdot \mathrm{s}^{-1}$.

Several studies have found that the responses of herbaceous wetland plants to warming are more complex than those of woody plants. Even for plants colonizing the same habitat, small temperature changes can produce significantly different response trends. Liao et al. (2016) and Wang et al. (2019) have shown that between 1985 and 2008, the temperature in the Napahai has increased by $1.2^{\circ} \mathrm{C}$, and the differential responses of dominant plants in the aquatic-terrestrial ecotone can directly affect the wetland type, distribution area, and landscape diversity. An in-situ comparative study on the four plant species $S$. tabernaemontani, Sparganium emersum, H. vulgaris, and Eleocharis liouana in the Napahai of Shangri-La found that compared with the control group, increased temperatures affect the growth of $S$. tabernaemontani and $H$. vulgaris by promoting aboveground stem vascular structure, whereas the development of $E$. liouana and of the underground stem vascular structure of $H$. vulgaris was impeded. Also, the biomass of S. emersum first increased and then decreased (Dong et al. 2014; Guan et al. 2018). Plants have a certain tolerance level to changes in temperature. Moderate warming will increase photosynthetic rate, stomatal conductance, transpiration rate, and other parameters that reflect photosynthetic gas exchange capacity, whereas further increases in temperature with impede these processes (Ruan \& Li 2001). At present, S. tabernaemontani grows in numerous aquatic-terrestrial ecotones on the Yunnan Plateau. It is the dominant plant species in the aquatic-terrestrial ecotone in ShangriLa, Lugu Lake, Dianchi Lake, and other places, indicating that the current temperature in Yunnan is generally suitable for its growth. However, with the predicted further increase in temperature, $S$. tabernaemontani may gradually become less competitive in plateau areas due to its inability to adapt to higher temperatures.

The responses of plant morphological and structural parameters to temperature correspond to the photosynthetic capacity. The stomata are the primary channels for plants to control water vapor exchange, and the greater the density and the smaller the size, the higher the sensitivity of stomatal opening and closing, the higher the rate of water vapor exchange, and the higher the water loss (Franks \& Beerling 2009). The vascular structure is the center of water and material transportation and distribution and the main structure to maintain the upright state of plants. The greater the vein density, the stronger the conveying capacity, enabling the plant to remain upright and stretched. The larger the vascular bundle structures, the more water, nutrients, and 
organic matter can be transported by a single vascular bundle, but the risk of cavitation of the vascular bundle is also higher (Chen et al., 2017). Therefore, when plants adapt to environmental stress, those with higher vascular bundle density and smaller tissue structure show increased photosynthetic productivity with transmission efficiency. On the other hand, plants with low vascular bundles density and larger tissue structure are at risk of vascular bundle cavitation, transporting large amounts of substances simultaneously to increase their photosynthetic production. The leaf epidermis and its appendages provide mechanical support and ultraviolet radiation resistance and prevent physical water loss (Ristic \& Jenks 2002). The small and tightly arranged epidermal cells can effectively reduce the water loss rate and maintain the moisture levels in plants (Sun et al. 2016). The cuticle can reduce water evaporation and increase refractivity, preventing plants from damages by intense radiation (Dylan et al. 2009). In this study, the increase in temperature significantly improved stomatal sensitivity and water loss capacity of the studied species while also increasing water and material support via higher vein density. However, the risk of cavitation blockage of the vascular bundle also increased (larger vascular bundle size), and the physical water retention capacity of the epidermis and the ability to protect the plant against UV damage decreased because of the decreased cuticle thickness. Under warming conditions, higher stomatal density and vein density correspond to lower photosynthetic rates. This is consistent with our previous research results for other plateau wetland plants. For example, increasing temperature will reduce the light saturation point, net photosynthetic rate, and other photosynthetic characteristics of Zizania latifolia, thereby decreasing the light use ability (Liu et al. 2017). In plateau areas, in addition to transporting water and materials, the vascular structure of wetland plants may also consume a considerable proportion to support the upright stature of plants. This is also related to the fact that wetland plants grow in water and are easily affected by the force of water currents. The significant positive correlation between photosynthetic rate and vascular bundle length indicates that maintaining an upright position of $S$. tabernaemontani is the prerequisite for photosynthetic production. At the same time, the smaller the vascular bundle reduces the lower the amounts of water and assimilates transported by a single vascular bundle under increasing temperatures. This directly manifests the decline in the photosynthetic capacity of $S$. tabernaemontani. At increasing temperatures, water loss through the stomata and the epidermis is high, and the photosynthetic activity of $S$. tabernaemontani is considerably more affected by stomatal sensitivity and epidermal water loss (thin cuticle) than by stomatal water loss (higher stomatal density). High stomatal water loss and low photosynthetic rate indicate that the water use efficiency of $S$. tabernaemontani is low. In addition to photosynthetic gas exchange, a large part of water is used for other purposes, such as physical cooling of leaves and stomatal opening to obtain more $\mathrm{CO}_{2}$. The photosynthetic rate was significantly positively correlated with cuticle thickness, indicating that water loss through the epidermis makes temperature reduction essential for promoting photosynthesis. Since $S$. tabernaemontani is an aquatic plant, it has unlimited access to water; however, in wetland habitats, the amount of available $\mathrm{CO}_{2}$ is limited. Under warming conditions, wetland plants may physically cool the leaves with large amounts of readily available water, obtaining limited $\mathrm{CO}_{2}$ amounts through the stomata (Zhang et al. 2007).

The concentration of $\mathrm{CO}_{2}$ is closely related to photosynthesis. Plants often show enhanced photosynthetic capacity as the $\mathrm{CO}_{2}$ concentration rises. However, over time, they adapt to these high concentrations, resulting in a "downregulation of photosynthesis" (Arp 1991; Kimball 1991). In our study, net photosynthetic rate, stomatal conductance, and transpiration rate of S. tabernaemontani showed a downward trend under the condition of doubled $\mathrm{CO}_{2}$ concentrations but did not reach significant levels. This is consistent with the findings of Jiang et al. (1997), who reported that in some plants, under high $\mathrm{CO}_{2}$ concentrations, photosynthesis is downregulated; however, the underlying mechanisms still need to be explored. According to previous studies, elevated $\mathrm{CO}_{2}$ concentrations can inhibit photosynthesis via changes in plant physiology and metabolism. Excessive $\mathrm{CO}_{2}$ concentrations ( $>700 \mu \mathrm{mol} \cdot \mathrm{mol}^{-1}$ ) in plants will affect the consumption capacity of triose phosphate and the regeneration ability of phosphate radicals in the photophosphorylation process, resulting in a decreased $\mathrm{CO}_{2}$ use, which in turn leads to a reduction in the photosynthetic rate (Farquhar 1980). Increasing atmospheric $\mathrm{CO}_{2}$ concentrations also increase the intercellular $\mathrm{CO}_{2}$ concentrations of plants, and to maintain a stable osmotic potential, plants will adjust the opening and closing of their stomata (Guan et al. 2019; Farquhar \& Sharkey 1982).

In our study, $S$. tabernaemontani showed a significant reduction in stomatal length and cuticle thickness under the condition of a doubled $\mathrm{CO}_{2}$ concentration, whereas stomatal density was substantially increased. This indicates a trade-off between stomatal and cuticle traits in the adaptation process. Similarly, Liu (2017) showed that the $\mathrm{CO}_{2}$ concentration regulates leaf wax 
synthesis by promoting or inhibiting the expression of leaf wax synthesis regulation genes. Increasing $\mathrm{CO}_{2}$ concentrations will significantly reduce leaf wax, which is consistent with the results of this study. Since an increase in $\mathrm{CO}_{2}$ reduces the wax synthesis of the leaves of $S$. tabernaemontani, which leads to a significant reduction in cuticle thickness, therefore, water is more likely to be lost through the leaves. The present study found a significant correlation between cuticle thickness and stomatal traits; to maintain its leaf water balance, the $S$. tabernaemontani responded by reducing its stomatal size and increasing its stomatal number, thereby reducing leaf water loss.

\section{Abbreviations}

Pn: Net photosynthetic rate

Gs: Stomatal conductance

Tr: Transpiration rate

SL: Stomatal length

SD: Stomatal density

VD: Vein density

CT: Cuticle thickness

ET: Epidermal thickness

EA: Epidermal cell area

VBL: Vascular bundle length

VBW: Vascular bundle width

VBA: Vascular bundle area]

CK: Control check

ET: Temperature increase treatment

EC: $\mathrm{CO}_{2}$ concentration doubling treatment

$\mathrm{CO}_{2}$ : Carbon dioxide

S. tabernaemontani: Schoenoplectus tabernaemontani

\section{Declarations}

\section{Acknowledgements}

This study was carried out in the National Plateau Wetlands Research Center, Southwest Forestry University, China. We would like to thank the institution for providing the space for Schoenoplectus tabernaemontani cultivation and the facilities required for this study.

\section{Funding}

This work was supported by the Yunnan Province Department of Education Research Fund (2019Y0142) and the National Natural Science Foundation of China (31760115). 


\section{Disclosure statement}

The authors have no conflicts of interest.

\section{Availability of data and materials}

The data that support the findings of this study are available from the corresponding author upon reasonable request.

\section{References}

1. Anderegg WRL, Klein T, Bartlett M, Sack L, Pellegrini AFA, Choat B, Jansen S (2016) Meta-analysis reveals that hydraulic traits explain cross-species patterns of drought-induced tree mortality across the globe. Proceedings of the National Academy of Sciences 113: 5024-5029

2. ARP WG (1991) Effects of source-sink relations on photosynthetic acclimation to elevated $\mathrm{CO}_{2}$. Plant Cell Environment $14: 869-875$

3. Bresson CC, Vitasse Y, Kremer A, Delzon S (2011) To what extent is altitudinal variation of functional traits driven by genetic adaptation in European oak and beech? Tree physiology 31:1164-1174

4. Chen XH, Xu Y, Liu H, Li Q, Kang XK (2017) Root/stem anatomical characteristics of four Malus plants in Western Sichuan Plateau and their drought adaptation strategy. Acta Botanica Boreali-Occidentalia Sinica 37(7):1296-1302

5. Day JW, Barras J, Clairain E, Johnston J, Justic D, Kemp GP, Ko J, Lane R, Mitsch WJ, Steyer G, Templet P, Alejandro YA (2005) Implications of global climatic change and energy cost and availability for the restoration of the Mississippi delt. Ecol Eng 24:253-265

6. Dong Y, Tian k, Xiao DR, Zhang K, Guo XH, Li J (2014) Impacts of regional climate condition variations on physiological and biochemical properties of aquatic plants in Napahai Wetland. Acta Ecol Sin 34(19):5570-5578

7. Dylan KK, Brice B, Amélie B, Eugene PP, Shiyou L, Jérôme J, Matthew AJ (2009) The Impact of Water Deficiency on Leaf Cuticle Lipids of Arabidopsis. Plant Physiol 151:1918-1929

8. Fang K (2003) Laboratory Examination of the Water Transportation of Plant Conduit. Journal of Mianyang Teachers' College 22(2):56-60

9. Farquhar GD, Caemmerer SV, Berry JA (1980) A biochemical model of photosynthetic $\mathrm{CO}_{2}$ fixati on in $\mathrm{C}_{3}$ species. Planta 149(1):78-90

10. Farquhar GD, Sharkey TD (1982) Stomatal Conductance and Photosynthesis. Annual Review of Plant Physiology 33(1):317-345

11. Feng CH, He ZP, Tian K, Guan DX, Liu ZY, Sun M (2019) Comparative study of functional adaptability of Scirpus Validus under different elevation. Journal of Southwest Forestry University (Natural Sciences) 39(1):166-171

12. Feng CH, Sun M, Tian K, Guan DX, Zhang YN (2020) Effect of Conducting Tissue of Scirpus validus to Simulated Warming. Journal of Northeast Forestry University 48(4):26-30

13. Feng ZZ, Li P, Zhang GY, Li ZZ, Ping Q, Peng JL, Liu S (2020) Impacts of elevated carbon dioxide concentration on terrestrial ecosystems: problems and prospective. Chinese Journal of Plant Ecology 44(5):461-474

14. Franks PJ, Beerling DJ (2009) Maximum leaf conductance driven by $\mathrm{CO}_{2}$ effects on stomatal size and density over geologic time. Proc Natl Acad Sci USA 106:10343-10347

15. Guan DX, Feng CH, Tian k, Wang ZB, Zhang YN, Sun M (2019) Responses of stem anatomical structure of a lakeside dominant plant Hippuris vulgaris to simulated warming in Napahai wetland. Chin J Ecol 38(6):1620-1628

16. Guan DX, Tian K, Wang ZB, Zhang YN, Feng CH, Sun M (2018) Response of vascular structure of a lakeside dominant plant species Hippuris vulgaris L. to simulated warming in Napahai wetland of Northwestern Yunnan. Chin J Ecol 37(9):26112618

17. Guittar J, Goldberg D, Klanderud K, Klanderud K, Telford RJ, Vandvik V (2016) Can trait patterns along gradients predict plant commu- nity responses to climate change? Ecology 97:2791-2801 
18. Han YQ, Liu X, Hu WP, Zhang PJ, Deng JC, Cheng ZL (2017) Effects of $\mathrm{CO}_{2}$ Enrichment on Chlorophyll Fluorescence Characteristics of Vallisneria natans. Bulletin of Botanical Research 37(1):45-51

19. IPCC (2014) Climate Change 2013: The Physical Science Basis. Bridge University Press, Cambridge

20. Jiang GM, Lin GH (1997) Changes of photosynthetic capacity of some plant species under very high $\mathrm{CO}_{2}$ concentrations in Biosphere 2. Chin Sci Bull 42(10):859-864

21. Kimball IBA (1991) Downward regulation of photosynthesis and growth at high $\mathrm{CO}_{2}$ levels: no evidence for either phenomenon in three-year study of sour orange trees. Plant Physiol 96:990-992

22. Lawren S, Kristen F (2006) Leaf structural diversity is related to hydraulic capacity in tropical rain forest trees. Ecology 87:483-491

23. Li LL, Jiang XQ, Liu QC, Liu QH, Sun YQ, Wang KL (2016) Adaptability of Camellia sasanqua leaf morphology during natural changes in temperature. Chin J Appl Ecol 27(9):2815-2822

24. Li W, He S (2018) The conservation and management of plateau wetlands in Yunnan Province, China. IOP Conference Series: Earth and Environmental Science 208

25. Liao J, Shen CM, Yu XS (2016) Climate Changes and Its Influence on Napahai Wetland. Journal of West China Forestry Science 45(4):136-140+ 146

26. Liu GY, Xie YC, Hou YH, Li X, Zhang HG, Wan YF (2018) Effects of elevated temperature and carbon dioxide concentration on the growth of Highland Barley. Chinese Journal of Agrometeorology 39(9):567-574

27. Liu XL (2017) Study on the synthesis and regulation of cuticular wax at high carbon dioxide concentration. Master thesis. Wuhan Botanical Garden of the Chinese Academy of Sciences

28. Liu ZY, Zhang XN, Li LP, Wang H, Zhang Y, Sun M, Xiao DR (2017) Influence of simulated warming on light and $\mathrm{CO}_{2}$ utilization capacities of lakeside dominant plants in a typical plateau wetland in northwestern Yunnan. Acta Ecol Sin 37(23):7821-7832

29. Qi CY, Yang SH, Zhong QC, Zhang C, Wang KY (2012) Responses of photosynthetic characteristics of Phragmites Australis to simulated temperature enhancement in Eastern Chongming Island, China. Journal of East China Normal University(Natural Science) 6:29-38

30. Ruan CJ, Li DQ (2001) Stomatal conductance and influence factors of seabuckthorn in Loess Hilly Region. Acta Botanica Boreali-Occidentalia Sinica 21(6):1078-1084

31. Ristic Z, Jenks MA (2002) Leaf cuticle and water loss in maize lines differing in dehydration avoidance. J Plant Physiol 159:0-651

32. Sack L, Ball MC, Brodersen C, Davis SD, Marais DLD, Donovan LA, Givnish TJ, Hacke UG, Huxman T, Jansen S (2016) Plant hydraulics as a central hub integrating plant and ecosystem function: meeting report for 'Emerging Frontiers. Plant Cell Environment 39:2085-2094 in Plant Hydraulics' (Washington, DC, May 2015)

33. Sun BW, Li RQ, Duan XC, Chang ZH (2016) Relationship between leaf morphology and physiological responses of perennial ryegrass under cold stress. Pratacultural Science 33(3):450-458

34. Sun M, Su T, Zhang SB, Li SF, Anberreelebreton J, Zhou ZK (2016) Variations in leaf morphological traits of Quercus guyavifolia (Fagaceae) were mainly influenced by water and solar irradiation at high elevations on the Qinghai-Tibet Plateau, China. International Journal of Agriculture Biology 18:266-273

35. Sun M, Yang SJ, Zhang JL, Bartlett M, Zhang SB (2014) Correlated evolution in traits influencing leaf water balance in Dendrobium, (Orchidaceae). Plant Ecology 215: 1255-1267

36. Vo TD, Nishihara GN, Kitamura Y, Shimada S, Kawaguchi S, Terada R (2015) The effect of irradiance and temperature on the photosynthesis of Hydropuntia edulis and Hydropuntia eucheumatoides (Gracilariaceae, Rhodophyta) from Vietnam. Phycologia 54: $24-23$

37. Wang Q, Tian Y, Xie T, Wang H (2017) Distinctive responses of photosynthetic characteristics to warming of invasive Alternanthera philoxeroides and native Sambucus chinensis. Acta Ecol Sin 37(3):770-777 
38. Wang QQ, Wang H, Zhang WG, Wang ZB, Xiao DR (2019) The correlations between wetland landscape and social-natural factors on Northwestern Yunnan Plateau. Acta Ecol Sin 39(2):726-738

39. Wright IJ, Reich PB, Westoby M, Ackerly DD, Baruch Z, Bongers F, Cavender-Bares J, Chapin T, Cornelissen JHC, Diemer M (2004) The worldwide leaf economics spectrum. Nature 428:821-827

40. Xia JY, Lu RL, Zhu C, Cui EQ, Du Y, Huang K, Sun BY (2020) Response and adaptation of terrestrial ecosystem processes to climate warming. Chinese Journal of Plant Ecology 44(5):494-514

41. Xu JP, Tian K, Sun M, Yuan J, Chen GL, Wu XY, Zhang XT (2016) The growth response of Scirpus validus to elevated $\mathrm{CO}_{2}$. Journal of Southwest Forestry University(Natural Sciences) 36(5):84-88

42. Yin HJ, Liu Q, Lai T (2008) Warming effects on growth and physiology in the seedlings of the two conifers Picea asperata, and Abies faxoniana, under two contrasting light conditions. Ecol Res 23:459-469

43. Zhang DW, Xing Y, Dang A (2007) Morphological anatomical studies on Aceraceae vessel element from Heilongjiang province, China. Bulletin of Botanical Research 27(4):408-411

44. Zhang M, Lin H, Long XG, Cai YT (2021) Analyzing the spatiotemporal pattern and driving factors of wetland vegetation changes using 2000-2019 time-series Landsat data. Sci Total Environ 780:1-15

45. Zhao CZ, Liu Q (2009) Growth and physiological responses of Picea asperata seedlings to elevated temperature and to nitrogen fertilization. Acta Physiol Plant 31:163-173

46. Zhao N, Li FR (2016) Effects of temperature rise on photosynthetic physiological characteristics of different life forms of plants. Ecology Environmental Sciences 25(1):60-66

47. Zuo WY, He JS, Han M, Ji CJ, Dan FBF, Fang JY (2005) Responses of plant stomata to elevated $\mathrm{CO}_{2}$ and temperature: observations from 10 plant species grown in temperature and $\mathrm{CO}_{2}$ gradients. Acta Ecol Sin 25(3):565-574

\section{Figures}



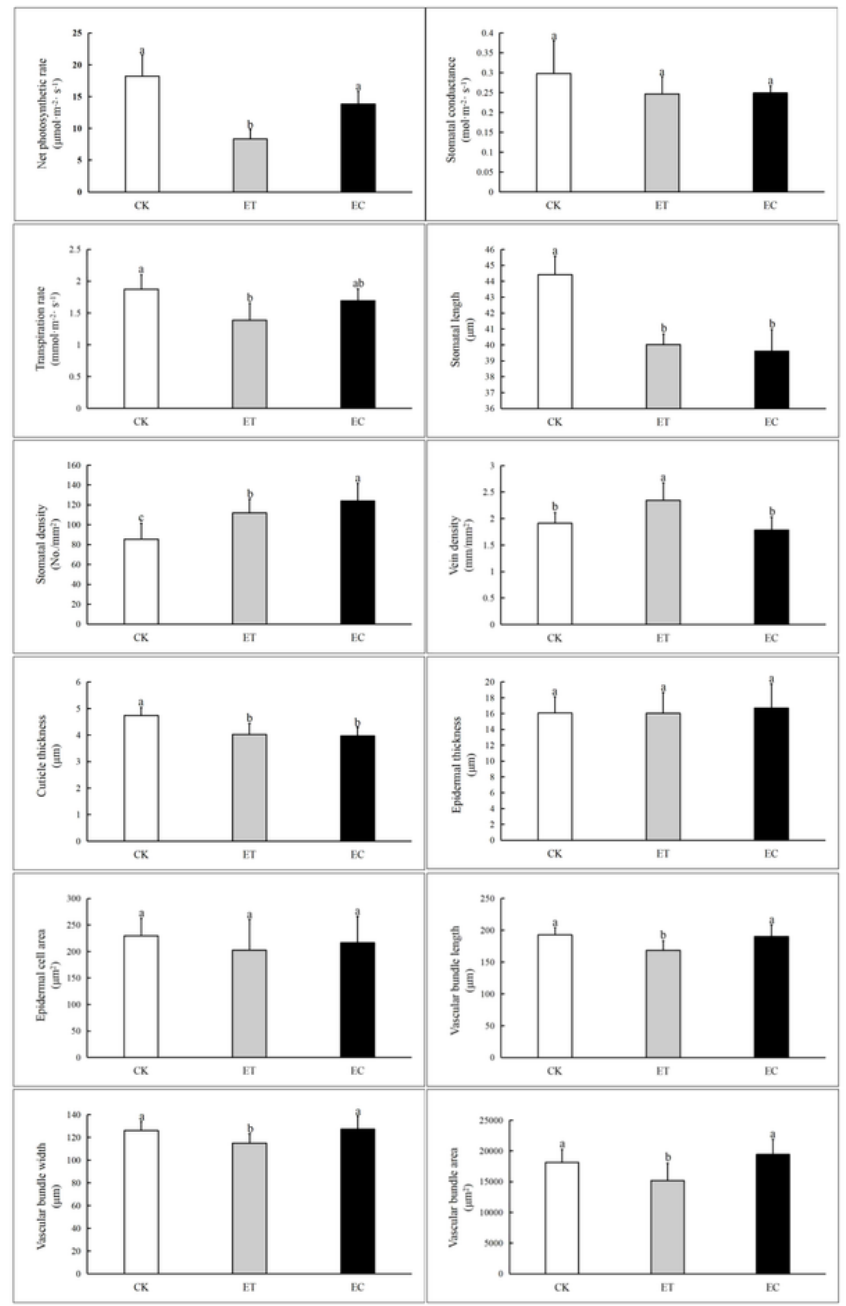

\section{Figure 1}

Differences in the hydraulic traits (mean \pm SD) of Schoenoplectus tabernaemontani among three groups subjected to different treatments. Different lowercase letters indicate significant differences at the 0.05 level $(P<0.05)$. CK: control group; ET: Warming group; EC: CO2 concentration doubling group. 


\section{Variables factor map (PCA)}

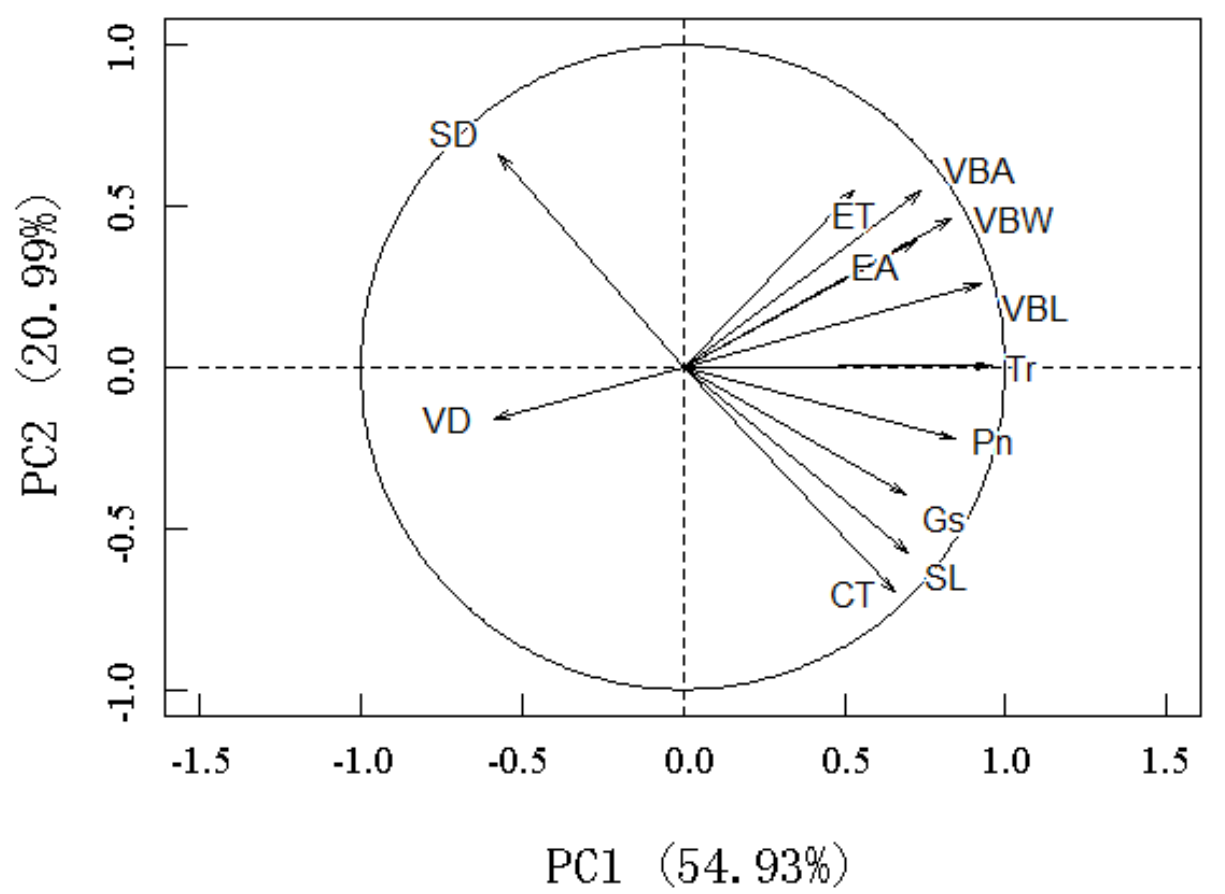

\section{Figure 2}

Principal components analysis showing the contribution of hydraulic traits of Schoenoplectus tabernaemontani to total variance and the relationships among the characteristics. Pn: Net photosynthetic rate; Gs: Stomatal conductance; Tr:

Transpiration rate; SL: Stomatal length; SD: Stomatal density; VD: Vein density; CT: Cuticle thickness; ET: Epidermal thickness; EA: Epidermal cell area; VBL: Vascular bundle length; VBW: Vascular bundle width; VBA: Vascular bundle area. 